\title{
Numerical simulation and analysis of aerodynamic drag on a subsonic train in evacuated tube transportation
}

\author{
Yaoping $\mathrm{ZHANG}^{1,2^{*}}$ \\ 1. Institute of Vacuum Tube Transportation, Xijing University, Xi'an 710123, China \\ 2. School of Transportation and Logistics, Southwest Jiaotong University, Chengdu 610031, China
}

\begin{abstract}
The aerodynamic drag on a train running in an evacuated tube varies with tube air pressure, train speed and shape, as well as blockage ratio. This paper uses numerical simulations to study the effects of different factors on the aerodynamic drag of a train running at subsonic speed in an evacuated tube. Firstly, we present the assumption of a steady state, two dimensional, incompressible viscous flow with lubricity wall conditions. Subsequently, based on the Navier-Stokes equation and the $k-\varepsilon$ turbulent models, we calculate the aerodynamic drag imposed on the column train with a 3-meter diameter running under different pressure and blockage ratio conditions in an evacuated tube transportation (ETT) system. The simulation is performed with FLUENT 6.3 software package. An analyses of the simulation results suggest that the blockage ratio for ETT should be in the range of 0.25-0.7, and the tube internal diameter in the range of 2-4 m, with the feasible vacuum pressure in the range of 1-10 $000 \mathrm{~Pa}$ for the future subsonic ETT trains.
\end{abstract}

Key words: subsonic train; evacuated tube transportation; aerodynamic drag; blockage ratio

(C) 2012 JMT. All rights reserved.

\section{Introduction}

$\mathrm{H}$ Igh-speed Maglev evacuated tube transportation (ETT) is able to run at supersonic and even hypersonic speeds [1-5]. The operation speed at the initial stage should be in the subsonic range of $500-1000 \mathrm{~km} / \mathrm{h}$. The train running in the evacuated tube is subjected to aerodynamic drag, the value of which is function of tube air pressures, train speed and shape, and blockage ratios. The study of the effects of various factors that affect aerodynamic drag on the ETT train is necessary for a complete understanding of ETT aerodynamics.

ETT trains should run in a closed vacuum (rarefied gas) surrounding. This is in contrast to the dense gas surroundings in the tunnel where high-speed trains typically run. Furthermore, ETT trains run in a finite space which is different from the infinite boundary surroundings where a space shuttle flies. ETT aerodynamics is a new subject different from tunnel and aviation aerodynamics. Zhou et al. [6-7] simulated the aerodynamic drag on a ETT train and the blockage ratio of the ETT tube through a train model with half-arch front and tail, and obtained dynamic trends of the relationship among the air pressure in tube, the train speed, and the tube

\footnotetext{
Received Aug. 31, 2011; revision accepted Oct. 28, 2011

${ }^{*}$ Corresponding author. Tel.: +86-29-85628051

E-mail: tubetrans@hotmail.com

(C) 2012 JMT. All rights reserved

doi: 10.3969/j.issn.2095-087X.2012.01.007
}

blockage ratio. However, they only considered speed under $200 \mathrm{~m} / \mathrm{s}$ and air pressures above $1000 \mathrm{~Pa}$.

This paper explores a wider calculation range, such as the ETT train speeds ranging from 50 to $300 \mathrm{~m} / \mathrm{s}$ and tube pressures from 10 to $10000 \mathrm{~Pa}$. Consequently, detailed numerical values of aerodynamic drag on the subsonic ETT train are obtained. Furthermore, this paper will search for an approach of selecting ETT tube section size from the aerodynamic consideration. Using FLUENT 6.3 software package, together with the assumptions of a steady two dimensional, incompressible viscous flow, and lubricity wall conditions, the NavierStokes equations coupled with $k-\varepsilon$ turbulent models are applied in simulating the aerodynamic drag imposed on ETT trains running at different vacuum degrees and blockage rate conditions [8-9].

\section{Calculation conditions}

\subsection{Basic consumptions}

(1) The gas in ETT tube is incompressible and viscous, with a flow field space that is two dimensional and steady [10].

(2) The inside wall of tube and train body are smooth.

(3) The gas density accords with standard gas state equation $p=\rho R T$, the gas pressure $p=\{10132.5,1013.25$, $101.325,10.1325\}(\mathrm{Pa})$ and $\rho=\{0.1225,0.01225$, $0.001225,0.0001225\}\left(\mathrm{kg} / \mathrm{m}^{3}\right)$. 
(4) Flow field Reynolds number $R e$ is defined in accordance with Refs. [11-13] as

$$
R e=\frac{\rho V L}{\mu},
$$

where the gas density $\rho=[0.0001225,0.1225]\left(\mathrm{kg} / \mathrm{m}^{3}\right)$, the speed of train $V=[50,300](\mathrm{m} / \mathrm{s})$, the characteristic length $L=6 \mathrm{~m}$, and viscous coefficient $\mu=[1.4216$, $1.7894]\left(\times 10^{-5} \mathrm{~Pa} \cdot \mathrm{s}\right)[12-13]$. Hence the minimum Reynolds number, $\min \{R e\}$ is given by the expression:

$$
\begin{aligned}
& \min \{R e\}=\frac{\min \{\rho V L\}}{\max \{\mu\}}= \\
& \frac{0.0001225 \times 9.8 \times 50 \times 6}{1.7894 \times 10^{-5}}=20127 .
\end{aligned}
$$

Since the minimum Re number is much more than 2000 , the flow is considered turbulent.

\subsection{Model geometry}

The geometry of the model used for calculating the aerodynamic drag is shown in Fig. 1. In the model, the ETT train is columned, with a diameter of $D_{1}=3 \mathrm{~m}$, body length $40 \mathrm{~m}$ and a semi-spherical front. The distance from the train front to the inlet of the vacuum tube is $80 \mathrm{~m}$, and the distance from the train tail to outlet is also $80 \mathrm{~m}$. The entire tube length is $200 \mathrm{~m}$, and the tube diameter $D_{0}$ used for calculating the aerodynamic drag is $3.6,4,5,6$ and $6.6 \mathrm{~m}$.

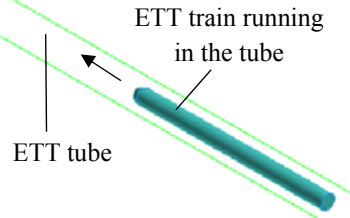

(a) 3D figure of the model geometry

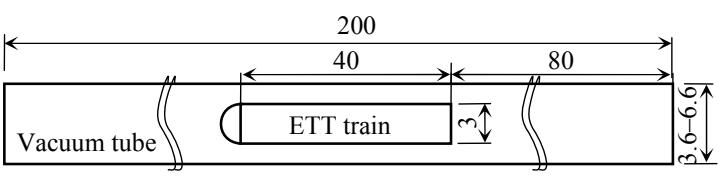

(b) Model geometry with size indication

Fig. 1 Model geometry (unit: $\mathrm{m}$ )

\subsection{Grid meshing by Gambit tool}

The meshing of the model geometry as appropriate on the basis of the blockage ratio was accomplished using Gambit software tool. The geometry of the model in this paper is assumed to be axis symmetric. In order to simplify the calculation and accelerate convergence, a half flow field calculation region is considered. A sketch of model grid meshing is shown in Fig. 2.

For simplicity, we assume a frame of reference in which the train is stationary, and the gas is in motion.

Fig. 2 2D model grid meshing

\subsection{Solver settings in FLUENT 6.3}

The main solver settings in FLUENT 6.3 are as follows:

- Solver: Pressure-based

- Space: 2D

- Formulation: Implicit

- Time: Steady

- Velocity formulation: Green-Gauss Cell Based

- Energy Equation: Not included

- Viscous mode: $k-\varepsilon$ (2 equation)

- $k-\varepsilon$ model: Standard

- Near-wall treatment: Standard wall functions

- Operating pressure: $0 \mathrm{~Pa}$

- Boundary conditions: Velocity-inlet and outflow

- Temperature: $300 \mathrm{~K}$

- Modified turbulent viscosity: $1.7894 \times 10^{5} \mathrm{~kg} /(\mathrm{m} \cdot \mathrm{s})$

\section{Calculation and analysis}

The aerodynamic drag imposed on ETT train is calculated according to the following equation:

$$
F=C_{\mathrm{d}} \cdot S / 1000,
$$

where $C_{\mathrm{d}}$ is the drag coefficient obtained from FLUENT simulation, in $\mathrm{N} / \mathrm{m}^{2} ; S$ is the train section area: $S=3.14 \times 1.5^{2}=7.065 \mathrm{~m}^{2}$.

When the air pressure intensity in ETT tube is $10132.5,1013.25,101.325$, and $10.1325 \mathrm{~Pa}$, different aerodynamic drags on the trains running in tubes under different blockage ratios and at different speeds are calculated and listed in Tables 1, 2, 3, and 4, respectively.

From Table 1, when the internal diameter of tube, $D_{0}$ is $6 \mathrm{~m}$, the blockage ratio $\alpha=0.25$ and train speed 
$V=300 \mathrm{~m} / \mathrm{s}$, the aerodynamic drag $F=46.165 \mathrm{kN}$, which is within the traction capacity range of common trains. It indicates that as long as the blockage ratio is less than 0.25 , the ETT train can run at a subsonic speed only when the air pressure in ETT tube is reduced to $1 / 10$ (about $10000 \mathrm{~Pa}$ ) of standard atmosphere pressure.

From Table 2, when the internal diameter of tube $D_{0}$ is $5 \mathrm{~m}$, the blockage ratio $\alpha=0.36$ and train speed $V=300 \mathrm{~m} / \mathrm{s}$, the aerodynamic $\operatorname{drag} F=31.156 \mathrm{kN}$, which is also within the traction capacity range of common trains. It indicates that as long as the air pressure intensity in ETT tube is reduced to $1 / 100$ (about $1000 \mathrm{~Pa}$ ) of standard atmosphere pressure, the tube internal diameter of $5 \mathrm{~m}$ can meet the requirement that the ETT train runs in subsonic range; namely the blockage ratio is increased to 0.36 . However, it should be noted that an aerodynamic drag of $31.156 \mathrm{kN}$ is still high for an ETT train. Thus, if we want to reduce tube section or increase blockage ratio, the air pressure intensity in tube must be reduced further.

From Table 3, when the inside diameter of tube $D_{0}=3.6 \mathrm{~m}$, the blockage ratio $\alpha=0.69$ and train speed $V=300 \mathrm{~m} / \mathrm{s}$, the aerodynamic $\operatorname{drag} F=15.550 \mathrm{kN}$, which is also within the traction capacity range of common

Table 1 Aerodynamic drags on trains running in ETT tubes at $10132.5 \mathrm{~Pa}$

\begin{tabular}{|c|c|c|c|c|c|c|c|c|c|c|}
\hline \multirow{2}{*}{$V(\mathrm{~m} / \mathrm{s})$} & \multicolumn{2}{|c|}{$D_{0}=6.6 \mathrm{~m}, \alpha=0.21$} & \multicolumn{2}{|c|}{$D_{0}=6 \mathrm{~m}, \alpha=0.25$} & \multicolumn{2}{|c|}{$D_{0}=5 \mathrm{~m}, \alpha=0.36$} & \multicolumn{2}{|c|}{$D_{0}=4 \mathrm{~m}, \alpha=0.56$} & \multicolumn{2}{|c|}{$D_{0}=3.6 \mathrm{~m}, \alpha=0.69$} \\
\hline & $C_{\mathrm{d}}$ & $F(\mathrm{kN})$ & $C_{\mathrm{d}}$ & $F(\mathrm{kN})$ & $C_{\mathrm{d}}$ & $F(\mathrm{kN})$ & $C_{\mathrm{d}}$ & $F(\mathrm{kN})$ & $C_{\mathrm{d}}$ & $F(\mathrm{kN})$ \\
\hline 50 & 163.66 & 1.156 & 174.05 & 1.23 & 1227.00 & 8.669 & 2991.06 & 21.132 & 6103.28 & 43.120 \\
\hline 100 & 666.82 & 4.711 & 706.98 & 4.99 & 4914.19 & 34.719 & 11964.51 & 84.529 & 24409.64 & 172.454 \\
\hline 150 & 1513.39 & 10.692 & 1605.89 & 11.35 & 11065.65 & 78.179 & 26934.85 & 190.295 & 54914.42 & 387.970 \\
\hline 200 & 2711.40 & 19.156 & 2876.36 & 20.32 & 19691.71 & 139.122 & 47879.68 & 338.270 & 97614.76 & 689.648 \\
\hline 250 & 4261.52 & 30.108 & 4518.48 & 31.923 & 30775.73 & 217.431 & 74805.10 & 528.498 & 152511.70 & 1077.495 \\
\hline 300 & 6223.30 & 43.968 & 6534.28 & 46.165 & 44316.75 & 313.098 & 107712.74 & 760.991 & 219607.63 & 1551.528 \\
\hline
\end{tabular}

Table 2 Aerodynamic drags on trains running in ETT tubes at $1013.25 \mathrm{~Pa}$

\begin{tabular}{|c|c|c|c|c|c|c|c|c|c|c|}
\hline \multirow{2}{*}{$V(\mathrm{~m} / \mathrm{s})$} & \multicolumn{2}{|c|}{$D_{0}=6.6 \mathrm{~m}, \alpha=0.21$} & \multicolumn{2}{|c|}{$D_{0}=6 \mathrm{~m}, \alpha=0.25$} & \multicolumn{2}{|c|}{$D_{0}=5 \mathrm{~m}, \alpha=0.36$} & \multicolumn{2}{|c|}{$D_{0}=4 \mathrm{~m}, \alpha=0.56$} & \multicolumn{2}{|c|}{$D_{0}=3.6 \mathrm{~m}, \alpha=0.69$} \\
\hline & $C_{\mathrm{d}}$ & $F(\mathrm{kN})$ & $C_{\mathrm{d}}$ & $F(\mathrm{kN})$ & $C_{\mathrm{d}}$ & $F(\mathrm{kN})$ & $C_{\mathrm{d}}$ & $F(\mathrm{kN})$ & $C_{\mathrm{d}}$ & $F(\mathrm{kN})$ \\
\hline 50 & 14.91 & 0.105 & 15.73 & 0.111 & 121.96 & 0.862 & 298.79 & 2.111 & 611.04 & 4.317 \\
\hline 100 & 61.56 & 0.435 & 64.56 & 0.456 & 488.71 & 3.453 & 1195.22 & 8.444 & 2442.81 & 17.258 \\
\hline 150 & 141.11 & 0.997 & 147.41 & 1.041 & 1100.58 & 7.776 & 2689.46 & 19.001 & 5494.82 & 38.821 \\
\hline 200 & 252.74 & 1.786 & 264.63 & 1.870 & 1958.03 & 13.833 & 4781.57 & 33.782 & 9767.52 & 69.008 \\
\hline 250 & 398.41 & 2.815 & 417.08 & 2.947 & 3060.89 & 21.625 & 7471.81 & 52.788 & 15259.89 & 107.811 \\
\hline 300 & 577.63 & 4.081 & 604.17 & 4.268 & 4409.91 & 31.156 & 10760.15 & 76.020 & 21972.78 & 155.238 \\
\hline
\end{tabular}

Table 3 Aerodynamic drags on trains running in ETT tubes at $101.325 \mathrm{~Pa}$

\begin{tabular}{|c|c|c|c|c|c|c|c|c|c|c|}
\hline \multirow{2}{*}{$V(\mathrm{~m} / \mathrm{s})$} & \multicolumn{2}{|c|}{$D_{0}=6.6 \mathrm{~m}, \alpha=0.21$} & \multicolumn{2}{|c|}{$D_{0}=6 \mathrm{~m}, \alpha=0.25$} & \multicolumn{2}{|c|}{$D_{0}=5 \mathrm{~m}, \alpha=0.36$} & \multicolumn{2}{|c|}{$D_{0}=4 \mathrm{~m}, \alpha=0.56$} & \multicolumn{2}{|c|}{$D_{0}=3.6 \mathrm{~m}, \alpha=0.69$} \\
\hline & $C_{\mathrm{d}}$ & $F(\mathrm{kN})$ & $C_{\mathrm{d}}$ & $F(\mathrm{kN})$ & $C_{\mathrm{d}}$ & $F(\mathrm{kN})$ & $C_{\mathrm{d}}$ & $F(\mathrm{kN})$ & $C_{\mathrm{d}}$ & $F(\mathrm{kN})$ \\
\hline 50 & 1.31 & 0.009 & 1.38 & 0.010 & 12.13 & 0.086 & 29.92 & 0.211 & 61.40 & 0.434 \\
\hline 100 & 5.47 & 0.039 & 5.70 & 0.040 & 48.57 & 0.343 & 119.60 & 0.845 & 245.07 & 1.731 \\
\hline 150 & 12.61 & 0.089 & 13.14 & 0.093 & 109.38 & 0.773 & 269.01 & 1.901 & 550.89 & 3.892 \\
\hline 200 & 22.74 & 0.161 & 23.71 & 0.168 & 194.60 & 1.375 & 478.16 & 3.378 & 978.82 & 6.915 \\
\hline 250 & 36.06 & 0.255 & 37.53 & 0.265 & 304.23 & 2.149 & 747.04 & 5.278 & 1528.80 & 10.801 \\
\hline 300 & 52.53 & 0.371 & 54.56 & 0.385 & 438.33 & 3.097 & 1075.68 & 7.600 & 2200.92 & 15.550 \\
\hline
\end{tabular}


Table 4 Aerodynamic drags on trains running in ETT tubes at $10.1325 \mathrm{~Pa}$

\begin{tabular}{|c|c|c|c|c|c|c|c|c|c|c|}
\hline \multirow{2}{*}{$V(\mathrm{~m} / \mathrm{s})$} & \multicolumn{2}{|c|}{$D_{0}=6.6 \mathrm{~m}, \alpha=0.21$} & \multicolumn{2}{|c|}{$D_{0}=6 \mathrm{~m}, \alpha=0.25$} & \multicolumn{2}{|c|}{$D_{0}=5 \mathrm{~m}, \alpha=0.36$} & \multicolumn{2}{|c|}{$D_{0}=4 \mathrm{~m}, \alpha=0.56$} & \multicolumn{2}{|c|}{$D_{0}=3.6 \mathrm{~m}, \alpha=0.69$} \\
\hline & $C_{\mathrm{d}}$ & $F(\mathrm{kN})$ & $C_{\mathrm{d}}$ & $F(\mathrm{kN})$ & $C_{\mathrm{d}}$ & $F(\mathrm{kN})$ & $C_{\mathrm{d}}$ & $F(\mathrm{kN})$ & $C_{\mathrm{d}}$ & $F(\mathrm{kN})$ \\
\hline 50 & 0.07 & 0.001 & 0.09 & 0.001 & 1.22 & 0.009 & 3.07 & 0.022 & 6.40 & 0.045 \\
\hline 100 & 0.36 & 0.003 & 0.42 & 0.003 & 4.84 & 0.034 & 12.08 & 0.085 & 24.80 & 0.175 \\
\hline 150 & 0.96 & 0.007 & 1.06 & 0.008 & 10.85 & 0.077 & 26.89 & 0.190 & 55.46 & 0.392 \\
\hline 200 & 1.83 & 0.013 & 2.02 & 0.014 & 19.23 & 0.136 & 47.89 & 0.338 & 98.60 & 0.697 \\
\hline 250 & 3.14 & 0.022 & 3.31 & 0.023 & 30.25 & 0.214 & 74.72 & 0.528 & 153.96 & 1.088 \\
\hline 300 & 4.44 & 0.031 & 4.74 & 0.034 & 43.61 & 0.308 & 107.81 & 0.762 & 221.65 & 1.566 \\
\hline
\end{tabular}

trains. It indicates that as long as the air pressure intensity in ETT tube is reduced to $1 / 1000$ (about $100 \mathrm{~Pa}$ ) of the standard atmosphere pressure, the tube inside diameter can be reduced to $3.6 \mathrm{~m} \mathrm{[14].} \mathrm{That} \mathrm{is,} \mathrm{the} \mathrm{blockage}$ ratio is increased to 0.69 , and the ETT train can run in the whole subsonic range.

From Table 4, for blockage ratio $\alpha=[0.25,0.69]$ and train speed $V=[50,300](\mathrm{m} / \mathrm{s})$, the aerodynamic drag is $F=[0.001,1.566](\mathrm{kN})$. It indicates when the air pressure intensity in ETT tube is reduced to $1 / 10000$ (about $10 \mathrm{~Pa}$ ) of the standard atmosphere pressure, for blockage ratio in any feasible range, the aerodynamic drag is reduced to a quite low level. For the ETT system, when the blockage ratio is greater than 0.7 , the structure of ETT train and tube section will become unreasonable. On the other hand, when the blockage ratio is less than 0.2 , the overmuch ETT tube section redundancy will make the ETT system uneconomical. Thus, this paper suggests $\alpha$ should be in the range of $0.2-0.7$ as a reasonable value for the blockage ratio of ETT system. Nevertheless, this does not necessarily imply that this value is the optimum.

\section{Conclusions}

The diameter of the column ETT train in the geometry model used for calculating the aerodynamic drag in this paper is $3 \mathrm{~m}$, which is close to the size of carriage of the current international standard railway. When the tube internal diameter is increased to $4 \mathrm{~m}$ and the air pressure in the tube is $10 \mathrm{~Pa}$, aerodynamic drag on the ETT train reduces. However, the increase in the diameter of ETT tube not only increases the construction costs of the ETT system, but also the costs associated with creating and maintaining the required vacuum surroundings. Therefore, it is recommended that the internal diameter of the ETT tube should not exceed $4 \mathrm{~m}$.

In the case of an air pressure of $10000 \mathrm{~Pa}$ in the ETT tube, if the blockage ratio $\alpha$ is very small, such as 0.25 , the aerodynamic drag on ETT train in subsonic range is also in the range of the train traction capacity. However, an increase of $\alpha$ increases the aerodynamic drag on an ETT train beyond the capacity range of traction that train can provide. Since a blockage ratio 0.25 is too small for ETT, the air pressure intensity in the future ETT system should be less than $10000 \mathrm{~Pa}$. This means that the blockage ratio of ETT should be more than 0.25 , so that the air pressure intensity in ETT tube can be further reduced so as to keep the aerodynamic drag on ETT train at a low level.

When the air pressure in ETT tube is $10 \mathrm{~Pa}$, the aerodynamic drag on trains running in subsonic range (up to $300 \mathrm{~m} / \mathrm{s}$ ) will not go beyond the train traction capacity. When the air pressure is less than $10 \mathrm{~Pa}$, ETT train running in a subsonic range will run in the surroundings almost without resistance.

From the above reasons, two important conclusions are obtained:

(1) Reasonable internal diameter of a subsonic ETT tube should be in the range of 2 to $4 \mathrm{~m}$.

(2) Reasonable air pressure in the subsonic ETT tube should be in the range of 1 to $1000 \mathrm{~Pa}$.

At the same running speed, the higher blockage ratio means the smaller tube section. As a result, the cost of the ETT tube construction and the cost of creating vacuum surroundings and maintaining vacuum will be low, but the vacuum degree in ETT tube need to be higher. The higher vacuum degree means higher cost in creating and maintaining vacuum. Thus, the optimum values of blockage ratio and vacuum degree needs to be determined by further analysis and comprehensive economic comparison.

\section{Acknowledgments}

The research is supported by the National Natural Science Foundation of China (No. 50678152), and the Scientific Plan Fund of Shaanxi Province (No. 2009K09-24). 


\section{References}

[1] Y.P. Zhang, D. Oster, A New Industial Era Coming: Primary Dialogue on Evacuated Tube Transportation, Beijing: Tsinghua University Press, 2004.

[2] B. Swartzwelter, Faster Than Jets: A Solution to America's Long-term Transportation Problems, Portland: Alder Press, 2003.

[3] D. Oster, M. Kumada, Y. P. Zhang, Evacuated tube transport technologies (ET3) ${ }^{\mathrm{tm}}$ : a maximum value global transportation network for passengers and cargo, Journal of Modern Transportation, 2011, 19(1): 42-50.

[4] Y.P. Zhang, Y.Y. Li, Role and Position of ETT in The Future Comprehensive Transportation System, In: The Proceedings of International Conference on Transportation Engineering 2007, Chengdu, China, July 22-24, 2007: 2796-2803.

[5] Y.P. Zhang, D. Oster, M. Kumada, et al., Key Vacuum Technologies to $\mathrm{Be}$ Solved in Evacuated Tube Transportation, Journal of Modern Transportation, 2011, 19(2): 110-113.

[6] X. Zhou, Y.P. Zhang, Y.F. Yao, Numerical simulation on the aerodynamic drag of high-speed train in evacuated tube, Science Technology and Engineering, 2008, 28(6):
1671-1819 (in Chinese).

[7] X. Zhou, D.Y. Zhang, Y.P. Zhang, Numerical simulation of blockage rate and aerodynamic dragof high-speed train in evacuated tube transportation, Chinese Journal of Vacuum Science and Technology, 2008, 28(6): 535538 (in Chinese).

[8] Y. Yu, Fluent Entrance and Promotion, Beijing: Institute of Technology Press, 2008 (in Chinese).

[9] Z.N. Wu, Aerodynamics (Part II), Beijing: Tsinghua University Press, 2007: 6 (in Chinese).

[10] Z.N. Wu, Aerodynamics (Part I), Beijing: Tsinghua University Press, 2007: 310-328 (in Chinese).

[11] X.Y. Wang, Aerodynamics Base, Xi'an: Northwestern Polytechnical University Press, 2006: 13 (in Chinese).

[12] Y.J. Qian, Aerodynamics, Beijing: Beijing University of Aeronautics and Astronautics Press, 2004: 403 (in Chinese)

[13] Z.Z. Han, Fluent Fluid Engineering Simulation Examples and Application, Beijing: Beijing Institute of Technology Press, 2010 (in Chinese).

[14] Y.P. Zhang, D. Oster, Primary analysis on tube section size of evacuated tube transportation, In: ICRE 2010 Proceeding, Beijing, Aug. 21-23, 2010: 67-72.

(Editor: Dongju CHEN) 